\title{
INFORMAÇÃO EM SAÚDE: POTENCIALIDADES E LIMITAÇÕES
}

\section{INFORMACIÓN EN SALUD: POTENCIALIDADES Y LIMITACIONES}

\author{
Maria das Graças Targino gracatargino@hotmail.com \\ Doutora em Ciência da Informação pela UnB. Pós-doutora pelo Instituto Interuniversitario de Ibe- \\ roamérica da Universidad de Salamanca (Espanha). Máster Internacional en Comunicación y \\ Educación Universidad Autónoma de Barcelona (Espanha). \\ Docente da Universidade Estadual do Piauí
}

\begin{abstract}
Resumo
Objetiva-se discutir a informação em saúde como elemento fundamental no processo de tomada de decisões no âmago das políticas públicas, visando elevar a qualidade de vida das nações. Para isto, a priori, discorre-se sobre os sistemas de informação em saúde. A partir daí, ressalta-se o processo de comunicação científica, incluindo a divulgação de resultados, com ênfase para as potencialidades e limitações da informação em saúde. Finalmente, apresentam-se sugestões, sobretudo, com vistas à popularização dessas informações.
\end{abstract}

\section{Palavras-chave}

Informação em saúde; Divulgação científica.

\section{PALAVRAS INICIAIS}

Diante da temática - informação em saúde - temos um binômio relevante e profícuo em discussão, tanto isoladamente como em conjunto, que traz subjacente a pesquisa científica como força motriz do processo de desenvolvimento de nações e povos. A princípio, a informação como característica da contemporaneidade, num processo crescente, ininterrupto e decisivo para a vida pessoal e profissional dos indivíduos e das coletividades. Segundamente, a informação em saúde como recurso fundamental para assegurar o bem-estar dos povos, haja vista que o indicador mais em voga para avaliar a qualidade de vida e o progresso humano no contexto mundial, o Índice de Desenvolvimento Humano (IDH), agrega três itens, dentre os quais está a longevidade, que diz respeito à esperança de vida ao nascer e reflete os padrões de saúde pública, nutrição e condições materiais de vida, fatores determinantes para definir o nível de qualidade das gerações. Além da longevidade, o IDH privilegia o nível educacional, alusivo à taxa de alfabetização da população adulta e à taxa combinada de matrícula nos ensinos fundamental, médio e superior, e um terceiro elemento, acesso a recursos, cujo indicador é a renda per capita. 
Discorrendo sucintamente acerca dos elementos enunciados, enfocamos, de início, a pesquisa e a informação. Independente das críticas que possam ser feitas à globalização, como elemento demolidor das fronteiras e da soberania nacional e instrumento de deculturação e / ou aculturação dos países periféricos, sob outro olhar, é ela que favorece acesso amplo, em nível mundial, a aplicações tecnológicas e a informações em todos os níveis. Ainda que ocorra desde longa data, o entrelaçamento econômico entre os povos intensifica-se a partir da segunda metade do século XX. O processo de globalização conduz à crescente integração das economias e dos países, sobretudo no que tange à produção de mercadorias e prestação de serviços, e aos mercados financeiros. Porém, extrapola a integração econômica e tecnológica e a padronização de mecanismos de produção com vistas à produtividade maior, para incorporar processos distintos, como a universalização de valores, a exemplo da liberdade e democracia, e a valorização de temas, como degradação ambiental.

Tudo isto pressupõe acesso às novas tecnologias de informação e de comunicação. Portanto, inferimos que o impulso para tais mudanças é a informação e a sua difusão. Daí, a sociedade contemporânea ter como eixo da economia a produção, distribuição e difusão da informação, perfazendo um novo setor do sistema produtivo, o quaternário, que engloba as atividades da indústria da informação e do conhecimento. A informação é, hoje, fator determinante da história da humanidade. Mas tal como a globalização, é ambivalente. Fortalece a democracia, ao favorecer o exercício da cidadania, o qual prevê acesso à informação para cumprimento de deveres e reivindicação de direitos. Em oposição, age como fator neocolonizador, ao contribuir para diferentes formas de dominação: econômica, política e cultural.

Como decorrência dessa valorização da informação, num processo irreversível, o desenrolar das atividades humanas, em todas as instâncias, depende cada vez mais da gestão técnica e científica. A simples união dos cientistas em torno de objetivos comuns não garante o desempenho da atividade científica. Este requer a formulação de políticas públicas abrangentes, definidas pelo Governo em consonância com os setores da sociedade civil, com destaque para a iniciativa privada, e que variam segundo o estágio desenvolvimentista das nações e regiões.

Os países do Terceiro Mundo, por exemplo, investem em ciência e tecnologia (C\&T) bem menos do que os centrais, priorizando a pesquisa aplicada. A este respeito, conforme o próprio Ministério da Ciência e Tecnologia (BRASIL, 2008a), a área de C\&T, de a- 
cordo com parâmetros internacionais, compreende as atividades de pesquisa e desenvolvimento experimental (P\&D) e as atividades científicas e técnicas correlatas (ACTC). Mas os recursos aplicados pelo Governo Federal e pelas empresas, bem como os valores constantes dos indicadores consolidados e das comparações internacionais referem-se apenas ao binômio P\&D, porquanto as discussões acerca dos procedimentos metodológicos inerentes aos investimentos em C\&T, relativos às ACTC ainda estão em andamento.

Independente dessas observações, o fato é que enquanto as nações avançadas destinam cerca de $3 \%$ do seu produto interno bruto (PIB) para a consecução de atividades científicas e tecnológicas, o Brasil, décima segunda economia do mundo (depois de ter ocupado a oitava posição, em 1998), ocupa o $30^{\circ}$ lugar no ranking científico mundial, com investimento de tão-somente $1,37 \%$ do seu PIB em C\&T, conforme dados de $2005^{1}$.

Dizendo de outra forma, diante da escassez de recursos, os pesquisadores e cientistas brasileiros, em saúde ou em qualquer outro campo, carecem de condições mínimas para a sua atuação. Entre elas, facilidade de acesso à informação, infra-estrutura adequada, possibilidade de comunicação com os pares em caráter permanente e sistemático e oportunidades para a divulgação ampla dos seus trabalhos, com base numa premissa elementar - a divulgação de resultados é etapa intrínseca e não complementar à pesquisa científica.

No que se refere ao terceiro elemento - informação em saúde - é essencial perceber a saúde como recurso básico de qualquer sociedade e, por conseguinte, a informação em saúde é fundamental ao processo de tomada de decisões no âmago das políticas públicas, objetivando elevar a qualidade de vida dos povos. Informações sobre perfil da morbidade e mortalidade, fatores de risco mais freqüentes e os seus determinantes, características demográficas e serviços de assistência médico-sanitária são imprescindíveis ao planejamento, à implantação, à implementação e à avaliação de ações e serviços de saúde, independente das especificidades das coletividades.

A função macro da informação em saúde é detectar problemas individuais e coletivos do quadro sanitário de uma população, oferecer elementos que subsidiem a análise rigorosa desse quadro e, então, apresentar alternativas para minimizar a situação encontrada. Para isto, em termos ideais, abrange tanto informações relativas ao binômio saúde $\mathbf{x}$ doença como as de natureza administrativa.

\footnotetext{
${ }^{1}$ BRASIL. Ministério da Saúde (MS). Webmasters dos indicadores de ciência e tecnologia. [mensagem pessoal]. Mensagem recebida por <gracatargino@hotmail.com> em 22 set. 2005.
} 
Diante do exposto, nosso objetivo central é discutir informação e saúde ou informação em saúde, sob a ótica da ciência da informação e da comunicação social, e, não, os sistemas de informação em saúde em si, tema de domínio total dos participantes do Seminário dos Projetos do Programa de Indução à Pesquisa \& Desenvolvimento Tecnológico, produzido pelo Instituto de Comunicação e Informação Científica e Tecnológica em Saúde (ICICT) da Fundação Osvaldo Cruz (Fiocruz), uma das pioneiras no País no estudo de doenças tropicais.

Para a consecução do proposto, a priori, discorremos sobre os sistemas de informação em saúde en passant. A partir daí, ressaltamos o processo de comunicação científica, incluindo a divulgação de resultados, com ênfase para as potencialidades e limitações da trajetória da informação em saúde.

\section{SISTEMAS DE INFORMAÇÃO EM SAÚDE}

\subsection{Aspectos Gerais}

Ao contrário do que podemos imaginar, a denominada explosão bibliográfica ou explosão informacional não acontece a partir da Internet. Inicia ainda no século XV, graças ao advento da escrita e da imprensa, que acarreta a laicização e popularização dos conhecimentos, alcançando o seu ápice no século XX, devido a uma série de fatores intervenientes. De forma sucinta: avanço da C\&T; incremento da investigação científica; aperfeiçoamento do processo de defesa nacional; exploração espacial; industrialização crescente; número elevado de pesquisadores; especialização mais e mais acentuada; possibilidade de impressão rápida; produtividade média por pesquisador estimada pelas agências de fomento à pesquisa em quatro artigos por ano; e, por fim, o impulso das novas tecnologias, com ênfase para a Internet.

Sob esta perspectiva, o aumento exponencial de registros informacionais provoca tanto reflexão acerca da distinção entre dados e informação, como a necessidade imperiosa de agregar informações sob uma visão sistêmica, a fim de facilitar o acesso. Quanto ao primeiro item, há nítida diferença entre os termos, com o adendo de que informação para alguém pode ser simples dado para outrem e vice-versa, face às particularidades intrínsecas aos nossos repertórios cognitivos. Os dados são tão-somente a matéria prima da informação, despojados de valor intrínseco. Dados brutos podem ser informação, mas não necessariamente. Para que isto se dê, devem ser imbuídos de forma e de significado. 
Datas de nascimento e / ou do primeiro parto são meros dados. Se devidamente explorados para comportar significados são transmutados em informação. Exemplificando: num estudo acerca da gravidez na adolescência, as datas de nascimento e parto mostram a incidência crescente ou não da ocorrência, e conduzem à compreensão mais ampla da sua problemática.

Como adendo, lembramos que há também distinção entre informação e conhecimento. A primeira constitui matéria-prima do segundo. Só é conhecimento a parcela dos elementos que se incorporam ao repertório cognitivo e conceitual do ser humano. Dentre o manancial de informações às quais temos acesso cotidianamente, só o que conseguimos reter, apreender e compreender é conhecimento. Resumindo: a informação é capaz de produzir conhecimento ou não, da mesma forma que ocorre com o dado em relação à informação. Esta pode atuar como formadora de estoque ou como agente modificador, capaz de gerar novos conhecimentos. No primeiro caso, tem-se a função estática da informação: estoques per se não são responsáveis pela concepção de conhecimentos e nem transmutam a realidade. Somente uma ação que se posicione como agente modificador confirma a produção do conhecimento.

Ao tripé - dados, informação, conhecimento -, acrescenta-se um novo elemento, a sabedoria, dentro da denominada "hierarquia quádrupla" de Mason (1990, apud TARGINO, 1998). Sabedoria na acepção de habilidade para gerenciar informações e conhecimentos, selecionando os mais relevantes em situações distintas, em meio ao processo de tomada de decisão. Trata-se do elemento mais importante para docentes e pesquisadores, uma vez que se refere ao modo de operacionalização das informações e conhecimentos assimilados, exercendo papel de destaque no processo de comunicação articulado pela comunidade científica.

Quanto ao segundo elemento, visão sistêmica, mesmo sem detalhar a Teoria Geral dos Sistemas, interessa-nos pensar sistema como um todo complexo e organizado, cujas partes intrinsecamente relacionadas perfazem dinamicidade sistemática e contínua, e cuja articulação visa a um fim comum. Laureni França (2002), ao estudar o comportamento informacional dos profissionais médicos e enfermeiros do Programa de Saúde da Família (PSF) do Sistema Único de Saúde (SUS), em Teresina, Piauí (PI), constata o sistema como ordem estática posta em movimento diante das ações efetivadas pelos indivíduos, no contexto de um ambiente dinamizado por propósitos e objetivos comuns. Tal dinamicidade concretiza-se em arranjos e ajustes de adaptação às mudanças, forjando ambientes 
de complexidade e caos, cujo movimento de organização / desorganização / reorganização resulta da tendência dos sistemas em busca do equilíbrio interno face ao ambiente externo.

Assim sendo, graças à força crescente da informação como fator de transmutações sociais e à concepção do sistema como princípio organizador do conhecimento, o significado da informação nos sistemas adota função estratégica. Isto significa que a informação nas organizações concilia metas e objetivos com formatos e conteúdos diversificados das diversificadas fontes de informação, estruturadas ou não, em sistemas disponibilizados no ambiente organizacional. As organizações são unidades sociais ou agrupamentos humanos, (re)construídos intencionalmente, com o fim de atingir metas previamente definidas. No caso, a garantia de uma população com mais saúde.

Porém, consensualmente, sabemos que as organizações em saúde apresentam significativa complexidade. Isto porque, as condições de saúde do indivíduo e da coletividade além de manterem diversidade, abrangência e evolução permanentes, envolvem fatores, sintetizados por França (2002). São eles: (a) objetivos de difícil definição e mensuração; (b) ações variáveis e, em sua maioria, emergenciais, além de pouco tolerantes a erros, o que demanda interdependência e inter-relacionamento entre profissionais e grupos profissionais; (c) integrantes altamente especializados e com nível de identificação maior com a profissão do que com as entidades onde atuam; (d) pouco controle efetivo sobre os profissionais da área médica como ordenador e gestor de despesas; (e) linha hierárquica de difícil compreensão, subsistindo, às vezes, linhas de autoridade múltiplas e implícitas.

\subsection{Sistemas de Informação em Saúde: Brasil}

Ora, se a informação circulante em qualquer organização guarda as características organizacionais enquanto elemento que inexiste fora de determinado contexto, no campo da saúde, no Brasil, a partir das últimas décadas do século passado, os sistemas informacionais conquistam espaço, face ao avanço de atividades setoriais, como vigilância epidemiológica, estatísticas vitais e administração de serviços.

Até mais ou menos os anos 70, os indicadores de saúde da população provinham de métodos indiretos, fundamentados em pesquisas amostrais ou em dados censitários gerados por órgãos de abrangência nacional e interesses não especializados, a exemplo do Instituto Brasileiro de Geografia e Estatística. Nas décadas de 70 e 80, os sistemas de 
informação em saúde refletem a atuação centralizadora do Estado, uma vez que o seu gerenciamento se situa na esfera federal. Os anos 80 e 90, por seu turno, já assistem à expansão dos sistemas de mortalidade, morbidade e nascidos vivos, com registro de informações municipais, não obstante à existência de falhas em sua cobertura, especialmente nos estados do Nordeste (NE) e Norte $(\mathrm{N})$. Isto Ihes impede de traçar mecanismos de gerenciamento compatíveis à realidade em saúde em questões básicas, como natalidade, migrações e mortalidade.

Mas, ainda com base em retrospectiva de Almeida e Alencar (2000), na década de 90, o Ministério de Saúde (MS), em ação conjunta com a Associação Brasileira de PósGraduação em Saúde Coletiva, imprime passo decisivo em direção à implantação, implementação e consolidação dos sistemas nacionais de informação em saúde, mediante diagnóstico dos sistemas com amplitude nacional, então existentes.

Identificados os problemas mais sérios, à época, falta de uniformidade da documentação dos sistemas, obstáculos para compatibilização das informações oriundas de diferentes sistemas, e, mais grave do que tudo, o difícil acesso às informações existentes, o Ministério revê a sistemática dos sistemas em funcionamento. Dentre eles, o Sistema de Informações sobre Mortalidade (SIM) e o Sistema de Informações de Nascidos Vivos (Sinasc). Edita, então, um manual de declarações de óbito (DO) e de nascimento (DN), tomando outras medidas que culminam com a informatização das atividades do SUS, dentro de diretrizes tecnológicas adequadas com vistas à descentralização das atividades de saúde e, por conseguinte, à viabilização e ao controle social sobre o uso dos recursos disponíveis.

E mais, ainda em 1996, o MS, junto com a Organização Pan-Americana de Saúde, institui a Rede Integrada de Informações para Saúde, matriz de indicadores básicos de saúde do Brasil, firmando-se como fórum técnico para as diferentes agências produtoras de informações de saúde e para os usuários, por seu nível de detalhamento, que inclui além da conceituação de cada indicador básico, o método de cálculo, as categorias e fontes.

Em termos gerenciais, o Departamento de Informação e Informática do SUS (Datasus) (BRASIL, 2008b), órgão da Secretaria Executiva do MS, assume o encargo de coletar, processar, armazenar e disseminar informações sobre saúde. Hoje, cobre informações distribuídas em sete blocos, todos eles com desdobramentos: (1) indicadores de saúde; (2) assistência à saúde; (3) rede assistencial; (4) morbidade e informações hospitala- 
res; (5) estatísticas vitais: mortalidade e nascidos vivos; (6) recursos financeiros; (7) informações demográficas e socioeconômicas. As suas representações estaduais constituem a linha de frente no suporte técnico às secretarias estaduais e municipais de saúde, sempre com o intuito de garantir a missão do Datasus, no sentido de prover os órgãos do SUS de sistemas de informação e suporte de informática imprescindíveis ao planejamento, à execução e ao controle do SUS, graças à manutenção de bases de dados nacionais, devidamente integradas.

Assim, como inevitável, à descentralização da gestão dos serviços de saúde corresponde à descentralização dos sistemas de informação, de tal forma que etapas antes efetivadas na esfera nacional são competência de órgãos estaduais e municipais. É o caso, por exemplo, da crítica dos dados, já feita diretamente nos softwares de entradas dos dados (ALMEIDA; ALENCAR, 2000).

Há, pois, na atualidade, significativos bancos de dados especializados. Os citados SIM e Sinasc. O primeiro provê informações para a definição de prioridades nos programas de prevenção e controle de doenças a gestores de saúde, pesquisadores e quaisquer interessados. A sua operacionalização se dá via preenchimento da $\mathrm{DO}$, sob o encargo das secretarias estaduais de saúde. Enquanto isto, o Sinasc fornece dados sobre nascidos vivos, incluindo elementos básicos: sexo, local de nascimento, tipo de parto, peso ao nascer, entre outros. No seu caso, o documento-padrão é a DN. Em ambos, os dados coletados são relevantes para a vigilância sanitária e análise epidemiológica, e, ainda, para estatísticas de saúde e demografia.

Contamos, ainda, com o Sistema de Informação de Agravos de Notificação (Sinan) e o Sistema de Informações Hospitalares do SUS (SIH-SUS). O Sinan coleta, transmite e dissemina dados gerados rotineiramente pelo sistema de vigilância epidemiológica do Governo, e, portanto, permite traçar e analisar o perfil de morbidade. Como decorrência, conduz a uma série de outras ações: diagnosticar a ocorrência de um evento na população; monitorar a saúde das coletividades; prever a ocorrência de eventos; gerar subsídios para explicações causais; antecipar riscos a que as comunidades estão sujeitas, e, sobretudo, contribuir com o planejamento da saúde populacional, definindo níveis de prioridade.

O SIH-SUS reúne informações que viabilizam o pagamento dos serviços hospitalares prestados pelo SUS, graças à captação de dados das autorizações de internação hospitalar, cuja média mensal extrapola mais de um milhão e 300 mil internações. Dispõe, 
portanto, de informes de suma importância em termos de saúde, tais como: recursos destinados a cada hospital integrante da ampla rede do SUS; causas mais freqüentes de internações; identificação dos procedimentos mais comuns nas diferentes regiões e estados brasileiros; total de leitos disponíveis para as especialidades; tempo médio de permanência dos pacientes na rede hospitalar etc.

No que tange aos dados ambulatoriais, não obstante a importância do Banco de Dados Nacional de Informações Ambulatoriais do SUS (BD-Siasus), do Sistema de Gerenciamento de Unidade Ambulatorial Especializada (Sigae), do Gerenciador de Informações Locais (GIL), enfatizamos tão-somente o Sistema de Informações Ambulatoriais do SUS (Siasus). Este oferece aos gestores estaduais e municipais de saúde, em consonância com as normas do MS, instrumentos para a operacionalização das funções de cadastramento, controle orçamentário, controle e cálculo da produção e para a geração de informações necessárias ao Repasse do Custeio Ambulatorial. E mais, segundo dados do Datasus, contém instruções imprescindíveis ao gerenciamento de capacidade instalada e produzida, e também, dos recursos financeiros estimados, orçados e repassados aos prestadores de serviços (BRASIL, 2008b, 2008c).

Merece menção também a atuação da Fiocruz, que se destina a "promover a saúde e o desenvolvimento social, gerar e difundir conhecimento científico e tecnológico, ser um agente da cidadania", o que justifica o investimento em sistemas e serviços de informação, com destaque para o Sistema Nacional de Informações Tóxico-Farmacológicas (Sinitox). O seu público-alvo extrapola as autoridades de saúde pública, os profissionais de saúde, para atingir a população em geral, informando sobre casos de intoxicação e envenenamento, por região geográfica. Além do Sinitox, a Fiocruz mantém distintas bases de dados: Rede de Bancos de Leite Humano; Biossegurança Hospitalar; Programa Integrado de AIDS [Acquired Immunodeficiency Syndrome] da Fiocruz; Programa Integrado de Esquistossomose; Sistema de Informação em Biossegurança; e Sistema de Informações Geográficas.

Na percepção de Mascarenhas (2004), essa proliferação de sistemas de informação em saúde, no País, resulta, sobretudo, de esforços empreendidos por profissionais envolvidos com saúde pública e epidemiologia, cuja função precípua em estudar as interrelações dos vários determinantes da freqüência e distribuição de doenças num conjunto populacional, demanda fluxo informacional contínuo e confiável. É a epidemiologia que favorece o reconhecimento dos problemas de saúde de cada região, provendo subsídios 
para a sua solução. Os dados que caracterizam o quadro epidemiológico correspondem a coeficientes e índices. São eles que conduzem ao diagnóstico de saúde, instrumento essencial para definir as ações mais adequadas para prevenir, minimizar ou solucionar os problemas detectados.

Os elementos necessários à elaboração desses coeficientes e índices são representados pelos dados vitais, de população e de doenças. Os dados vitais são os registros concernentes ao número de nascimentos vivos, nascimentos mortos, óbitos, casamentos, divórcios, adoções, legitimações, reconhecimentos, anulações e separações. Mello Jorge (1990) ainda acrescenta dados relativos à estrutura da população, à morbidade, ao nível socioeconômico, aos serviços e às atividades sanitárias, além das condições de moradia e ambientais. Como perceptível, os dados vitais são relevantes, em todas as instâncias, porque interferem nas relações pessoais e sociais, com reflexos na área de Direito, além de essenciais à saúde pública, ao favorecerem a fixação de coeficientes e índices usados para mensurar o nível de saúde da população.

Historicamente, na Antiguidade, nascimentos e óbitos mereciam registro, mas com finalidade unicamente tributária e / ou militar, a fim de se conhecer o contingente populacional apto para guerrear. Posteriormente, a Igreja Católica toma para si o registro dos dados vitais. Mais uma vez, o intuito não é a precisão demográfica, e sim, facilitar a cobrança dos eventuais serviços prestados pelo clero. Sem parâmetros previamente definidos, a sua aleatoriedade traz inconsistência tanto em qualidade como em quantidade.

Isto começa a mudar ainda no século XV, em países, como Espanha, França, Suécia, Finlândia e Dinamarca, mas apenas no século XVII, o registro de eventos vitais começa a ser utilizado com propósitos que não os civis. John Graunt, estatístico inglês, figura como o "pai" da demografia ou das estatísticas vitais, mediante a edição de um tratado sobre as tabelas mortuárias de Londres, onde analisa a mortalidade por sexo e região. Assim, pouco a pouco, como Mascarenhas (2004) chama a atenção, os registros paroquiais, em diferentes países, são substituídos por aqueles feitos pelo Estado, que assume a inscrição dos fatos e não mais somente de cerimônias, como nascimentos, batismos, casamentos, óbitos etc., o que lhe permite traçar quadros estatísticos.

$\mathrm{Na}$ realidade brasileira, a produção estatística remonta ao século $\mathrm{XVI}$, quando o $\mathrm{Pa}$ dre José de Anchieta registra a população de 57 mil habitantes, no trabalho intitulado L'information, confirmando a ingerência da Igreja no assunto. A organização do registro civil pelo Governo se inicia ainda no século XIX, graças à regulamentação do registro de 
nascimentos, casamentos e óbitos. No século seguinte, ele passa a disciplinar de modo mais rigoroso os registros públicos. De início, em termos jurídicos, a Lei № 6.015, de 31 de dezembro de 1973, dispõe sobre os registros públicos, incluindo ao lado do registro civil de pessoas naturais, o registro de pessoas jurídicas, de títulos e documentos e até mesmo de imóveis.

E aqui está um dos fatores que terminam por intervir no gerenciamento dos sistemas de informação em saúde, ainda que indiretamente. Se atualizações contínuas evidenciam a tentativa de o Poder Legislativo acompanhar as transformações inerentes a qualquer tecido social, a excessiva mobilidade das leis vigentes pode causar instabilidade e interferir na sua apreensão por parte do grande público. E, de fato, a Lei supracitada tem sofrido alterações freqüentes. Deixando de lado aquelas que não se relacionam diretamente com o registro civil dos indivíduos, identificamos, a partir de 1973, seis dispositivos que alteram o seu teor. Somente para dar noção da variação sofrida, e permitir aos interessados complementar as informações, até onde pudemos perceber, são eles: Lei № 7.844 (18 de outubro de 1989); Lei № 9.053 (25 de maio de 1995); Lei № 9.534 (10 de dezembro de 1997); Lei № 9.812 (10 de agosto de 1999); Lei № 9.997 (17 de agosto de 2000) e Lei № 10.215 (6 de abril de 2001).

O fato é que, com ou sem alterações, na atualidade, como bem explorado por Mascarenhas (2004), as estatísticas populacionais não são utilizadas prioritariamente nem para fins religiosos nem para fins militares e eleitorais. Ao contrário. Fundamentam o processo decisório, no âmbito governamental, em diversas esferas de atuação, com a intenção precípua de combater as disparidades econômicas entre regiões e classes sociais, as quais provocam reflexos perversos nos setores fundamentais da vida nacional, como educação, saneamento, habitação, alimentação, transporte, seguridade social, e, sobretudo, saúde pública.

\section{INFORMAÇÃO EM SAÚDE E COMUNICAÇÃO CIENTÍFICA}

Após visualizarmos a complexidade dos sistemas de informação em saúde, abordamos o universo inesgotável da comunicação científica. É ela que permite aos membros da comunidade científica, o intercâmbio de informações, num ciclo inesgotável, o qual incorpora medidas, facilidades, ocasiões, publicações, recursos e diretrizes de diferentes natu- 
rezas, que determinam como as mensagens científicas são transmitidas. Isto evidencia que a comunicação científica se fundamenta na informação científica. Esta, por sua vez, gera o conhecimento científico. Em sua essência, este representa o acréscimo ao entendimento universal vigente sobre fatos ou fenômenos. Isto porque a ciência possui caráter evolutivo e mutável, o que faz da pesquisa científica o seu instrumento-mor e da comunicação científica o seu elemento básico.

É a informação como essência da comunicação científica. Inevitavelmente, cientistas, pesquisadores e docentes em saúde são, ao mesmo tempo, produtores e consumidores de informação, ou seja, "prosumidores". De forma sistemática e contínua, permutam informações com os seus pares, e tal como ocorre no espaço cibernético, recebem (input), processam / apreendem (processing) e repassam informações (output), perfazendo um ciclo contínuo de dados.

E a comunicação científica inclui características e estágios distintos, que interagem, numa espécie de gradação, que vai do informal para o formal, perpassando pelo semiformal até alcançar a comunicação eletrônica. Aqui, valem três ressalvas. Primeiro, tal categorização não constitui unanimidade entre os teóricos. Em vários momentos, mostra-se frágil diante das perspectivas específicas dos diferentes campos. Segundo, os meios eletrônicos tendem a alterar consubstancialmente o processo de difusão do conhecimento, e, portanto, a forma de atuação e concepção dos canais de comunicação. O terceiro argumento é que formal, informal e eletrônico privilegiam mais a produção do artefato (documento) do que os aspectos comportamentais presentes no processo de comunicação (TARGINO, 1998).

\subsection{Comunicação científica formal}

Reiteramos que a comunicação científica formal se dá por meio da comunicação escrita, com destaque para livros, periódicos, obras de referência, relatórios, revisões de literatura, bibliografias de bibliografias etc., motivo pelo qual é denominada de comunicação escrita. Compreende tanto as publicações primárias, onde, pela primeira vez, os resultados das pesquisas são relatados ao público, como publicações secundárias e terciárias, advindas das primárias, uma vez que as resumem e indexam.

Os veículos formais de comunicação mantêm como vantagens a possibilidade de alcançar público amplo, além de armazenagem e recuperação seguras, volume moderado de informações redundantes, maior rigidez e controle graças à avaliação prévia. Em posi- 
ção contrária, face ao intervalo relativamente longo para difusão, apresentam risco permanente de informações transmitidas mui tardiamente, ou seja, estão sujeitos à desatualização veloz, não obstante as diferenças significativas existentes entre diferentes áreas e diferentes objetos de estudo.

\subsection{Comunicação científica informal}

A comunicação informal tem como marco a rapidez do fluxo informacional, e, portanto, maior atualização e menor custo, assegurando aos autores feedback quase que imediato para a revisão dos seus produtos, porquanto utiliza canais informais, em que a transferência da informação se dá via contatos interpessoais ou quaisquer recursos destituídos de formalismo. É a comunicação direta pessoa a pessoa ou comunicação oral. Incorpora formas públicas de troca de informações, tais como reuniões científicas, conferências, colóquios, seminários e congêneres ou participação em associações profissionais e colégios invisíveis, e também, formas particulares ou privadas, como conversas, telefonemas, cartas, fax, visitas in loco a centros de pesquisa e laboratórios.

Numa época em que o lema publish or perish, ao mesmo tempo em que estimula a produção, acarreta maior número de fraudes, ao lado de contribuições superficiais, inconsistentes, fragmentárias, o sistema informal assegura maior proteção aos autores, no momento em que, com rapidez, informa trabalhos ainda em andamento, não importa o estágio dos estudos. Um outro ponto positivo do sistema informal é que provê informações úteis para o trabalho rotineiro, a exemplo do que acontece no reduto tecnológico.

Em contraposição, apresenta desvantagens. Por priorizar a oralidade e / ou a informalidade, atinge público limitado e a sua redundância é bastante significativa. Ademais, apresenta problemas pertinentes à armazenagem e recuperação da informação, ao acesso e à disseminação. Por ser flexível e fluida, corre o risco de se perder num curto espaço de tempo, além de dificultar a sua análise e o seu controle e favorecer a inserção de novos conhecimentos sem avaliação prévia.

No caso específico da comunicação informal verbal, falta a permanência da palavra escrita. Os indivíduos têm memória limitada e nem sempre perfeita, razão pela qual, não raramente, a transferência ulterior das informações sofre alterações, sejam elas supressões ou acréscimos ou mesmo distorções. O conteúdo de uma conversa consiste, muitas vezes, em sondagem sobre uma idéia qualquer, com chances de ser totalmente modificada, sendo impossível controlar as informações intercambiadas e avaliar a sua influência 
para a investigação científica em andamento. Além disto, o acesso, por ser restrito e limitado, torna-se elitista e fechado.

\subsection{Comunicação científica eletrônica}

As interações mediadas eletronicamente continuam a reconfigurar a tessitura social e a identidade cultural dos povos, rompendo a compressão da distância e da escala de tempo. Hoje, o sistema de decisão é planetário, sem fronteiras ou limites. Dentro de um novo modelo co-informativo, distributivo, dinâmico e hipertextual, de estrutura horizontal e vertical, as redes eletrônicas de comunicação permitem que receptores e emissores assumam o papel de agente e interatuem com maior agilidade, precisão e consistência. Apontam para a perspectiva de de-massificação da sociedade, em contraposição aos meios de comunicação de massa tradicionais, os quais incentivam a homogeneização de hábitos, costumes e atitudes, em perspectiva vertical, ou seja, no modelo in-formativo, em que o emissor manipula as probabilidades de transmissão de dados.

Mesmo assim, a maioria dos estudiosos continua incluindo a comunicação que se concretiza através de meios eletrônicos, magnéticos ou óticos, no âmbito da comunicação informal (e-mails, bate-papos, grupos de discussão etc.) ou formal (periódicos científicos eletrônicos, obras de referência eletrônicas etc.). De qualquer forma, há tênue distância entre as formas de comunicação, até porque se a cultura impressa pode guardar marcas concomitantes da cultura oral, escrita e eletrônica, da mesma forma, a eletrônica pode conservar características das demais.

Em termos gerais, a comunicação científica eletrônica é a transmissão de informações científicas por intermédio de meios eletrônicos, sob duas perspectivas: (1) processo de mudanças estruturais induzidas tecnologicamente, ou seja, resultantes das inovações tecnológicas; (2) recurso capaz de incrementar o contato entre os cientistas.

E, sem dúvida, o avanço das novas tecnologias tem sido imensurável. Mais de 1.800 conferências anuais on-line nos mais diferentes campos criam espaços sociais, onde membros da comunidade acadêmica de todo o mundo interagem. Tais canais favorecem a manutenção dos laços informais em substituição ao contato face a face, e incentivam a interdisciplinaridade, ao criarem oportunidades de acompanhamento de áreas afins, rompendo a tradicional segmentação das disciplinas acadêmicas. Na contemporaneidade, grande parte do material publicado em papel tem, simultaneamente, cópia disponível em computador. Milhões de informações antes inatingíveis ou atingíveis após longo período se encontram ao alcance do grande público, vencendo dificuldades, como restrições dos 
países ou as instituições de origem; formas de difusão; e precariedade do processo editorial das publicações acadêmicas e especializadas.

No entanto, a comunicação eletrônica enfrenta entraves. O pesquisador precisa aprimorar a sua postura seletiva, recorrendo a mecanismos distintos, que incluem desde 0 simples hábito de leitura de resumos / abstracts à priorização de publicações especializadas, e, ainda, o domínio dos procedimentos de uso das novas tecnologias. Uma prova evidente é a busca da expressão - health information - no google, um dos buscadores de maior utilização no mundo. O resultado aponta para um bilhão 190 mil referências. Restringindo-se para a língua portuguesa - sistemas de informação em saúde - são um milhão e 450 mil sites disponíveis, que decrescem para 677 mil, se o termo de indexação é sistemas de informação em saúde + Brasil e para 241 mil, se digitamos - sistemas brasileiros de informação em saúde. Isto é, o internauta enfrenta a ineficácia de ferramentas de busca, o "lixão" cibernético e a lentidão dos downloads, com o agravante de que a Internet faz jorrar publicações eletrônicas, mas estas, não são necessariamente contribuições científicas.

Persistem, ainda, problemas acerca da autoria e propriedade intelectual, embora já existam numerosos trabalhos que tratam da questão do copyright no meio eletrônico. Perduram indagações sobre controle bibliográfico, armazenagem, conservação e custos, até porque muitas informações gratuitas são agora pagas.

Por outro lado, mesmo sem a rigidez e o controle do terreno formal, as informações eletrônicas não têm a fragilidade das apresentações orais, quanto ao processo de armazenagem e de recuperação. Não obstante as críticas constantes dos que sustentam que a tecnologia deve permitir ao usuário interface amigável para acessar quaisquer e todos os periódicos eletrônicos, ainda constitui prática comum a impressão. Isto garante a preservação da informação e a sua utilização posterior, pois o risco de as inovações que afetam programas e equipamentos transformarem os primeiros fascículos eletrônicos em material inacessível é real e está também atrelado ao nosso apego cultural ao papel.

São freqüentes também as indagações quanto à consistência das informações distribuídas, à avaliação pelos pares, à fidedignidade, e, em especial, à propalada atualização. Por exemplo, estudo efetivado em 2002, por Targino e Castro, acerca do Grupo de Publicações Eletrônicas em Medicina e Biologia (Grupo e-pub), programa nacional dedicado à produção de títulos científicos eletrônicos nas áreas de biologia, medicina e saúde, constata que os 14 títulos editados, ainda que mostrando traços marcantes de títulos ele- 
trônicos - interação usuário x periódico; utilização da navegação hipertextual e da multimídia - e com acesso irrestrito, mantêm, à época, pontos extremamente negativos. $\mathrm{O}$ índice elevado de 64,29\% conserva versão impressa, e 50\% dos títulos mantêm periodicidade irregular, com constantes atrasos e interrupções. Pior do que isto, $64,29 \%$ estão interrompidos ou suspensos e todos (sem exceção) sofrem processo de atraso, contrariando as expectativas de imediatismo do terreno eletrônico. Ora, este fato em si é grave, pois agrava a falta de credibilidade dos e-journals, ao acentuar a sensação de fluidez.

Enfim, a comunicação eletrônica guarda traços dos sistemas formal e informal, com maior inclinação para o informal. Como os formais, atinge público potencialmente amplo, e a seleção de canal e de conteúdo é de responsabilidade do pesquisador. Só que, tal como o informal, permite acesso a dados recentes e dá respostas imediatas aos autores, apesar de apresentar volume de redundância, às vezes significativo, e não passar pelo crivo da comunidade científica, salvo cuidados recentes e crescentes concernentes à editoração eletrônica de periódicos científicos.

\section{INFORMAÇÃO EM SAÚDE E DIVULGAÇÃO CIENTÍFICA}

As colocações acerca da comunicação científica têm um único intuito, qual seja, mostrar a força da divulgação científica no âmbito da pesquisa científica em qualquer área, mas com muita propriedade no caso da pesquisa envolvendo saúde. Afinal, trata-se de tema prioritário para todos os segmentos populacionais, de modo que, mais do que nunca, os pesquisadores devem propalar os seus achados, recorrendo a meios variados e múltiplos, por uma razão unívoca: ciência é uma atividade social.

Mesmo assim, as agências brasileiras de financiamento, em geral, continuam solicitando aos bolsistas a apresentação de relatórios revestidos de academicismo, e aos cursos de pós-graduação, as "célebres" monografias, nos seus diferentes níveis. Poucas vezes, trabalhos de conclusão de curso de graduação ou de especialização, e até dissertações e teses deixam os arquivos ou as estanterias das bibliotecas. Em geral, apresentam circulação ínfima. É preciso inovar e ousar, dando conhecimento à sociedade que nos financia do que estamos produzindo nos muros de nossas instituições, por meio de estratégias mais acessíveis. E, neste sentido, o Seminário dos Projetos do Programa de Indução à Pesquisa \& Desenvolvimento Tecnológico da Fiocruz reforça a nossa batalha nem silenciosa e nem intermitente em busca de romper os grilhões da "verdade" científica em 
direção a verdades palatáveis pelo grande público ou pelo menos para o público interno das instituições.

Para tanto, podemos e devemos utilizar os sistemas de comunicação informal, formal e eletrônico, recorrendo a veículos diversificados. Todos são elementos de divulgação: apresentações orais; relatórios; resumos; trabalhos em anais; artigos de periódicos impressos e eletrônicos; matérias jornalísticas; folhetos; correios eletrônicos; livros; dissertações; teses etc., até porque alguns têm circulação restrita e / ou se enquadram na concepção de literatura cinzenta, sendo sempre imprescindível adaptar a divulgação dos resultados das pesquisas aos públicos diferenciados. Inexiste inconveniente no desdobramento de dissertações e teses em artigos de periódicos e até em livros (mediante boa adaptação), ou na transformação de relatórios em artigos, disponibilizados em meios formais, informais e eletrônicos. Não importa. Vale tudo.

Em se tratando das revistas eletrônicas, há duas opções: acesso restrito e acesso aberto. Segundo Márdero Arellano, Ferreira e Caregnato (2005), as revistas de acesso restrito prevalecem como o modelo predominante de publicação científica, mantendo proximidade com as versões impressas, até mesmo quanto ao sistema avaliativo. $\mathrm{O}$ acesso a seu conteúdo é pago, tanto por meio de assinaturas individuais como de licenças de acesso a opções distintas de pacotes, sob a responsabilidade de distribuidores e / ou editores especializados. No caso das licenças em pacotes, pode ocorrer (e ocorre), que as entidades acabem por assumir o pagamento de títulos não selecionados. No Brasil, por conta da iniciativa do Portal Capes (Coordenação de Aperfeiçoamento de Pessoal de Nível Superior), raras são as bibliotecas que assinam tais contratos.

No que respeita às revistas de acesso aberto, não significam necessariamente gratuidade. O movimento do acesso aberto (Open Access) apóia o modelo de publicação pago pelo próprio autor, e também o modelo de auto-arquivamento de e-prints via protocolo de arquivos abertos. A priori, acesso aberto significa a disponibilização livre na Internet de literatura de caráter acadêmico ou científico, permitindo a qualquer interessado utilizar qualquer texto integral dos documentos. É o resultado do acordo denominado de Budapest Open Access Initiative. Esta declaração realça as iniciativas dos arquivos abertos e do acesso aberto como recurso para incrementar o avanço científico e tecnológico, em âmbito mundial, mediante a disseminação irrestrita de artigos científicos dos mais distintos campos do saber, resistindo às pressões da indústria editorial e dos órgãos públicos que mantêm acervos valiosos para pesquisas. 
As revistas eletrônicas de livre acesso comportam duas modalidades: as revistas gratuitas para o leitor e autor; as revistas gratuitas para os leitores, mas pagas pelos autores. As primeiras, em geral, são iniciativas não comerciais relativamente simples, envolvendo instituições acadêmicas ou sociedades científicas e profissionais. No segundo caso, os custos são pagos pelos próprios autores ou por suas instituições, o que assegura o acesso ao público e um padrão elevado de qualidade. Mas, como somente os artigos aceitos são pagos, as grandes revistas, que, com freqüência, recebem um número de submissões bem superior ao de aceites, enfrentam custo de processamento elevado. Como decorrência, os artigos publicados saem a um preço elevado, sobretudo, para os pesquisadores das nações periféricas.

A este respeito, a fonte The United Kingdom Parliament (2004) exemplifica, calculando que, se a revista Nature, cujo índice de rejeição chega a 90\%, adotasse tal modelo, o seu custo de publicação oscilaria entre 10 a 15 mil dólares por cada texto. Talvez, a solução seja a cobrança dos manuscritos submetidos, aceitos ou não. Mas, corroboramos Márdero Arellano, Ferreira e Caregnato (2005), de que se trata de uma alternativa de publicação científica, que ainda tem longo caminho a trilhar, mesmo na área de saúde, até que, inclusive culturalmente, assimilemos o hábito de pagar por nossos escritos. E repetimos: o pagamento deve ser responsabilidade das instituições de pesquisa a que os autores estão vinculados ou devem ser previstos como etapa intrínseca à realização da pesquisa científica.

Exemplos de títulos de acesso aberto estão na Public Library of Science (PLoS, 2008), organização sem fins lucrativos e gerenciada por cientistas, com o intuito de abrir as portas do conhecimento científico, dando a qualquer cientista, pesquisador, paciente ou estudante - de qualquer país - chance de acesso ilimitado às informações em saúde recém-geradas. No momento, são cinco títulos no campo das ciências da vida: PLoS Biology; PLOS Medicine; PLoS Computational Biology; PLoS Genetics e PLoS Pathogens. Segundo compromisso da PLoS, eles mantêm as características mais relevantes das revistas científicas, quais sejam, revisão dos pares e padrões editoriais e de produção extremamente rigorosos, com a vantagem de disponibilizar o seu conteúdo on-line de imediato, sem custos e sem restrições de acesso.

Registramos, ainda, a BioMed Central (2008), editora comercial, também na área biológica e da saúde, com mais de 100 títulos no sistema Open Access: os resultados de pesquisa estão de imediato e permanentemente disponíveis on-line sem cobrança de ta- 
xa, mas alguns títulos exigem assinatura institucional ou individual, no caso de acesso a outros tipos de textos, como revisões de literatura ou relatórios. Dentre as especialidades contempladas estão: biotecnologia, câncer, doenças cardiovasculares, farmacologia, patologia clínica, dermatologia e endocrinologia.

Na América Latina, a Universidad Nacional Autónoma de México mantém o Sistema Regional de Información en Línea para Revistas Científicas de América Latina, el Caribe, España y Portugal. Além de prover informações adicionais sobre um conjunto selecionado de revistas por meio de catálogo e manter um índice para remissão a recursos eletrônicos, o Latindex produz um diretório com mais de 12 mil títulos de revistas, incluindo as de acesso aberto.

Ainda na América Latina, a primeira iniciativa de acesso aberto ao conteúdo integral de periódicos científicos em várias áreas é o Projeto SciELO ou Scientific Electronic Library Online (http://www.scielo.br), resultante de proposta da Fundação de Amparo à Pesquisa do Estado de São Paulo (Fapesp) em parceria com o Centro Latino-Americano e do Caribe de Informação em Ciências da Saúde (Bireme). O seu propósito é desenvolver uma metodologia comum para preparação, armazenamento, disseminação e avaliação da produção científica em formato eletrônico. De início, o SciELO contemplava apenas títulos brasileiros. No momento, está sendo utilizado em outras nações. Dentre elas, Chile, Cuba e Espanha, e em fase de implementação, na Argentina, Venezuela, Colômbia, bem como em Costa Rica, no México e Peru.

Independente dessas publicações de teor científico, os pesquisadores em saúde não podem perder de vista a possibilidade de o público suprir as suas demandas informacionais no espaço cibernético, independente das dificuldades antes relatadas, exemplificada pelo "lixão" cibernético. Ao ingressar e "passear" na Rede, o cidadão comum pode desvendar o mundo antes restrito aos profissionais da saúde. Em matéria jornalística brasileira recente, o infectologista David Uip admite as mudanças comportamentais no vasto campo da informação por parte dos médicos, afirmando, literalmente:

O médico não é mais um deus impositivo que decide o que quer e acabou. Hoje ele tem de estar mais atualizado do que nunca para atender à expectativa de seus pacientes. Não tem como não ser assim na área da Internet. O saldo positivo disso tudo é que médicos que não estavam habituados a conversar detalhadamente com seus pacientes estão tendo de mudar de atitude (BUCHALLA, 2005, p.115).

Porém, insistimos que, se a Internet dá à população a chance de melhor se informar, e, portanto, cobrar bem mais da classe médica, em contraposição, pode gerar desinfor- 
mação e situações de pânico e insegurança. Tanto pela falta de credibilidade ou fidedignidade de muitos sites, cuja seleção requer capacidade de discernimento e bom senso, nem sempre ao alcance dos leigos, como também pela incapacidade desses indivíduos em apreenderem e absorverem as informações, enquanto não detentores de conhecimentos específicos.

Assim, a solução está na triagem das fontes eletrônicas consultadas. Para tanto, o público pode contar com o auxílio dos profissionais da área ou de veículos formais e informais. Exemplificando, a matéria supracitada, com base em consulta a especialistas, arrola os 10 melhores sítios de consulta de saúde internacionais e mais 10, nacionais, em segmentos, como: saúde e bem-estar, bem-estar, AIDS, câncer, coração, diabetes, cirurgias, mal de Alzheimer e medicamentos. Surpreendentemente, de acordo com quatro fontes - Associação Médica Americana, Pew Internet \& American Life Project, Health on the Net Foundation e Maxpress Net, oito em cada 10 internautas já buscaram alguma informação sobre saúde na Rede. Os temas de maior incidência são: doenças específicas (66\%); tratamentos médicos e dieta e nutrição, ambos com idênticos $51 \%$; exercícios físi$\cos (42 \%)$; remédios $(40 \%)$; tratamentos alternativos $(30 \%)$; busca por médicos e hospitais especializados (28\%); depressão, ansiedade e estresse (23\%); saúde sexual (11\%), problemas com álcool e drogas (8\%) e , por fim, como abandonar o tabagismo, com 7\% (BUCHALLA, 2005).

E ainda em relação à potencialidade inesgotável da divulgação científica em prol da informação em saúde, há um número razoável de editoras virtuais, a exemplo da Editco Comercial Ltda. ou leditora (http://www.ieditora.com.br), responsável pela divulgação de muitos trabalhos acadêmicos em rede, sem que isto represente custos adicionais para os pesquisadores. Citamos, ainda, a Papel Virtual Editora (http://www.papelvirtual.com.br), neste caso, mediante cobrança ao pesquisador, e que prioriza a edição virtual de livros, dissertações e teses.

Neste momento, lembramos que, se a divulgação de resultados ocorre, a princípio, no âmago da comunidade científica, não pode se limitar a ela. É preciso superar a prática tendenciosa da comunicação tão-somente para e entre cientistas e para e entre acadêmicos, num processo quase inconsciente de se "escrever para o próprio umbigo". Se a comunicação científica é básica àqueles que fazem ciência, a produção da ciência não se dá alheia ao contexto social em que se insere. Por conta de sua natureza eminentemente social, deve romper as fronteiras da comunidade de usuários mais imediatos, sob o risco 
de se tornar estéril e inútil, e compartilhar os conhecimentos científicos recém-gerados com toda a sociedade.

Isto requer aproximação maior entre jornalistas e cientistas, dentro do universo do jornalismo científico. Jornalistas e cientistas têm, sim, formações distintas e utilizam métodos de trabalho distintos, mas ciência e jornalismo não são esferas nem autônomas nem antagônicas. Podem e devem atuar de forma complementar em prol da comunidade, mediante interação que exige dos jornalistas aprimoramento de sua formação científica e dos cientistas um voto de confiança e de credibilidade em relação aos meios de comunicação.

Enquanto os teóricos em comunicação discutem os conflitos entre as duas categorias profissionais - cientistas e jornalistas - alegando os primeiros a falta de critério na notícia veiculada na mídia, os jornalistas contra-argumentam. Afirmam que os cientistas se fecham numa "redoma de marfim", ocultando das coletividades, por meio de uma linguagem hermética e inacessível, os resultados de suas investigações, quando, ironicamente, elas são efetivadas em nome de melhor qualidade de vida e dos preceitos contemplados por índices, como o citado IDH.

Mas, um ponto controverso é que há nítida tendência para valorização dos profissionais que estão na mídia por parte da população. Recentemente, por exemplo, em outdoor estampado em toda a cidade, uma faculdade particular teresinense convida a população para palestra a ser proferida pelo profissional $\mathbf{x}$. Como chamamento, utiliza a sua presença em quadro televisivo, como se fora uma credencial para assegurar a sua credibilidade como profissional e especialista. Ademais, cada vez mais, hospitais, clínicas, planos de saúde etc. recorrem à publicidade via "informes de saúde" ou similares, mas inevitavelmente impregnados de tom comercial.

Vemos, portanto, que não há regras rígidas e nem parâmetros universais. É o profissional de saúde em interface com a informação em saúde, o que requer compreensão da sua função eminentemente social e conscientização de que, em termos concretos, a divulgação das pesquisas em saúde é a arma mais suave para combater a natureza mística do "cientismo" (identidade de uma nova religião) e conquistar o cientificismo, compreendido como o apoio social e cultural ao trabalho dos cientistas. Tal apoio está vinculado ao valor que os diferentes segmentos sociais dão às pesquisas executadas, à sua concepção acerca da ciência, das suas funções e utilidades, à garantia de retorno social dos in- 
vestimentos, pois acreditamos que a opinião pública pode ser decisiva na fixação das políticas públicas.

\section{INFORMAÇÃO EM SAÚDE: POTENCIALIDADES E LIMITAÇÕES}

\subsection{Natureza intrínseca à informação em saúde}

Tudo discutido até então dá ideia de que informação em saúde abrange facetas diversas e diversificadas, intrínsecas à sua natureza. Exemplificando, o fato de a saúde ser em si mesma área abrangente, ao tempo em que tal abrangência traz consigo um mundo inesgotável de possibilidades e potencialidades, traz também uma série de limitações face à complexidade subjacente.

\subsection{Diversidade dos sistemas de informação}

De forma similar, a diversidade dos sistemas de informação mencionados ao longo do texto constitui potencialidade e limitação. Potencialidade por se tratar de estratégia essencial para abranger as diferentes e inevitáveis especialidades da área médica, que tendem a crescer a cada dia, como decorrência do avanço da C\&T, dentro do irrefutável: a compartimentação da ciência e do vasto campo da saúde integra a inesgotabilidade do conhecimento científico e sua provisoriedade.

No entanto, se todos os sistemas em vigor têm função definida e imprescindível não podem prescindir de supervisão sistemática e cuidadosa, diante da dimensão territorial deste Brasil, que traz no seu bojo, brasis multicolores ou em preto e branco. Isto é, a diversidade agrava as dificuldades de gerenciamento dos sistemas de informação em saúde, à semelhança do que se dá com a flutuação da legislação em temas diretamente vinculados à saúde pública, como vimos com a Lei № 6.015 .

A título de exemplo, a dificuldade de controle social está presente no estudo recente de Mascarenhas (2004, p. 42). Ao avaliar a confiabilidade do Sinasc em Teresina (PI) identifica duas limitações. De início, constata o mau preenchimento das fontes de registro hospitalar, com dados ignorados ou sem preenchimento acima de $10 \%$. A partir daí, um visível paradoxo: maior índice de informações no Sinasc, cujos informes se originam da DN, preenchida, por sua vez, com base nos prontuários. Mas estes apresentam percentual de preenchimento menor. Surge, assim, a segunda limitação: "a impossibilidade de i- 
dentificar qual a melhor fonte de dados, pois se pode ter um Sinasc com informação de qualidade superestimada e registros hospitalares aceitáveis ou o contrário."

Enfim, é a tão propalada fragilidade de estatísticas nacionais. Salvo engano, concordamos todos, que é sempre difícil traçar diagnósticos, em termos locais ou de Brasil, por um motivo básico. Diagnóstico pressupõe, sempre, conhecimento sobre determinada situação, a partir de estudo profundo fundamentado em dados precisos. Mas nos defrontamos, com freqüência, com dados imprecisos e inexatos. Isto porque, salvo honrosas exceções, há carência de pessoal devidamente técnico capacitado para exercer funções burocráticas ou técnicas, em saúde e fora dela. É a recorrente falta de padrões definidos. Sobre este tópico, reforçamos a importância do projeto realizado no âmbito da Fiocruz. Alice Ferry Moraes e sua equipe, com a proposta Ensino e pesquisa da Fiocruz: produtores científicos, buscam padronizar as entradas dos produtores, visando identificar e localizar a produção científica dos que integram a Fundação, onde quer que esteja publicada, e sob quaisquer normas diferentes, nos vários suportes informacionais, incluindo bancos de dados e de conhecimentos.

\subsection{Informação eletrônica em saúde}

A própria informação eletrônica em saúde carece de estudos não apenas sobre sua utilização pelo povo e pelos especialistas, mas também acerca de seus próprios procedimentos de operacionalização. É inquietante a constatação de França (2002). A amostra de 87 (43 médicos e 44 enfermeiros) profissionais, equivalente a $62 \%$ do total dos componentes das 70 equipes do PSF, também em Teresina, revela comportamento informacional surpreendente. Poucos freqüentam bibliotecas ou centros de documentação (32,56\%), e pior do que isto, somente $29,55 \%$ acessam as informações eletrônicas disponibilizadas pelo Datasus.

Justificam este resultado, face à indisponibilidade de computadores nas unidades básicas de assistência à saúde: os médicos, com 57,14\% e enfermeiros, com $66,67 \%$. Independente dos brasis distintos e das disparidades econômicas e sociais entre as regiões e classes sociais, com reflexos perversos na saúde, é difícil que o universo estudado tenha comportamento informacional radicalmente distinto dos demais Estados, pelo menos do N e NE, onde Almeida e Alencar (2000) comprovam maior incidência de falhas no registro de informações municipais sobre saúde do que nas outras regiões. 
Trata-se de dado preocupante. Se os profissionais envolvidos com um programa como o PSF, de ampla repercussão e abrangência nacional, utilizam as informações online com parcimônia, o que dizer do público em geral? Transcorridos mais de três décadas, o diagnóstico dos autores supra, ao que parece, persiste atual, ao apontar, dentre questões preocupantes acerca dos sistemas nacionais de informação em saúde, a falta de uniformidade dos sistemas e a dificuldade de acesso às informações existentes.

E se a Internet é primordial como apoio ao processo de educação continuada de qualquer profissional, inclusive o da área de saúde, não é panacéia para as questões informacionais da sociedade contemporânea. Ao contrário. Tem efeitos colaterais. Entre eles, promove um novo tipo de exclusão, a digital. É desconfortante assistir seminários ${ }^{2}$ sobre o Programa Fome Zero destinado exclusivamente para estratos sociais em situação de vulnerabilidade social, para não dizer de miséria, em que os administradores e acadêmicos envolvidos recheiam suas falas com citações a sites, correios eletrônicos etc. Além disto, há o risco já mencionado de a Internet trazer à tona informes inconsistentes, alarmistas e incompletos, desinformando mais do que esclarecendo.

Portanto, novamente, temos um elemento que representa, simultaneamente, potencialidade e limitação. Na Rede, vale o jogo de separar o joio do trigo, o que pressupõe cuidados mínimos sintetizados por Tomáel et al. (2001), para quem a mensuração de qualidade da Internet como fonte de informação e fontes de informação na Internet passam por tais parâmetros:

- informações de identificação - dados detalhados da pessoa jurídica / física responsável pelo site de modo a permitir a sua identificação plenamente;

- consistência das informações - detalhamento e completeza das informações fornecidas: cobertura da fonte, abrangendo informação da área que se propõe; validade do conteúdo em relação às demandas informacionais do internauta; existência de resumos ou de outros elementos complementares; coerência na exposição do conteúdo etc.;

- confiabilidade das informações - autoridade ou responsabilidade do mantenedor da fonte; autor, pessoa física, reconhecido em seu campo de atuação;

\footnotetext{
${ }^{2}$ Referimo-nos ao Seminário Estadual de Controle Social da Política de Segurança Alimentar e Nutricional (13 a 14 de maio de 2005) e ao II Seminário Regional Fome Zero Norte / Nordeste (15 a 17 de junho de 2005), ambos em Teresina - PI.
} 
conteúdo relacionado com a área de atuação do autor; referências a outros trabalhos do autor; endereço para contato com o autor; nível de atualização etc.

- adequação da fonte - coerência da linguagem utilizada pela fonte com o público a que se destina; coerência do site onde a fonte está localizada com o seu propósito etc.

- links - manutenção tanto de links internos como externos, para facilitar a navegação na própria fonte ou em outras fontes / sites de informação;

- facilidade de uso - facilidade para explorar / navegar no documento;

- lay-out da fonte -utilização de recursos atraentes e variados, recorrendo a som, imagens fixas ou em movimento e som; coerência entre as várias mídias (texto $\mathbf{x}$ som $\mathbf{x}$ imagem) etc.;

- restrições percebidas - existência de restrições mínimas ao acesso; não ocorrência de mensagens de erro durante a navegação; etc.

- suporte ao usuário - elementos de auxílio ao internauta, tal como: e-mails, informações de ajuda na interface.

\subsection{Pesquisas de caráter interdisciplinar}

A renomada Sociedade Brasileira de Estudos Interdisciplinares da Comunicação (Intercom) mantém distintos núcleos de pesquisa, dentre os quais o Núcleo de Pesquisa em Comunicação Científica e Ambiental, que abrange quatro subáreas: divulgação científica; comunicação rural; comunicação ambiental; comunicação e saúde. Dentre o período de 2002 a 2005, o segmento saúde é sempre o de menor representatividade, com percentuais irrisórios e decrescentes em relação ao total de papers aceitos: 2002, 20,83\%; 2003, 17,39\%; 2004, 8,70\% e 2005, 8\%. E o mais preocupante: grosso modo, os estudos são meramente descritivos (por exemplo: incidência do tema - saúde - nos veículos de comunicação), sem alcance social.

É um dado comprobatório do aspecto restritivo das pesquisas envolvendo saúde, embora, como vimos antes, pesquisa, informação e comunicação científica se entrelaçam de forma irremediável. Afinal, se, em termos genéricos, o aspecto personalizado da atividade médica assume inegável relevância, face à qualificação técnico-científica como condição essencial, aliada à relativa autonomia do seu desempenho e caráter intelectual, a- 
lém de normas sólidas de conduta ética, é de se esperar que a atividade médica interaja com a comunicação social para repercutir no âmago da sociedade.

\section{CONSIDERAÇÕES FINAIS E SUGESTÕES}

Em suma, informação em saúde está intrinsecamente vinculada à pesquisa em saúde, que se constitui per se em fonte inesgotável de novos saberes, haja vista a dinamicidade inerente à própria ciência. Reconhecendo, então, os avanços advindos não apenas da evolução científica e tecnológica, mas, sobretudo, dos esforços empreendidos pelo Datasus, ao recorrer às novas tecnologias, admitimos que há, na atualidade, bem mais agilidade tanto na produção como na disseminação das informações em saúde.

Algumas informações estão acessíveis com poucos meses de defasagem da ocorrência do evento, como no caso do SIH-SUS e do Siasus e as informações de mortalidade e de nascidos vivos respeitam a eventos ocorridos no máximo há dois anos atrás, tal como se dá em países avançados, como Estados Unidos da América e Inglaterra (ALMEIDA; ALENCAR, 2000; MASCARENHAS, 2004). Como conseqüência, essa disseminação mais abrangente favorece ao público informações em níveis distintos, nacional, regional, estadual e municipal, suscitando novos questionamentos e críticas mais pontuais, ideais como feedback para a melhoria da qualidade das informações disponibilizadas.

No entanto, como o processo de descentralização dos sistemas de informação nem sempre foi acompanhado de mecanismos gerenciais dos sistemas, tal ausência pode provocar distorções na coleta de informações em nível local. Porém, a bem da verdade, os pontos de estrangulamento identificados por Almeida e Alencar (2000) evidenciam que não advêm apenas da inexistência ou precariedade de mecanismos gerenciais dos sistemas, e sim, da exclusão social de parcelas significativas da população brasileira, localizadas prioritariamente, nas regiões $\mathrm{N}$ e NE, onde está a maioria das famílias em situação de extrema pobreza (com renda familiar mensal per capita de até 50 reais) e em situação de pobreza (com renda familiar mensal acima dos 50 reais), segundo parâmetros classificatórios adotados para o atual Programa Fome Zero do Governo Federal.

Afinal, tomando como parâmetro os Objetivos de Desenvolvimento do Milênio, definidos em setembro de 2000, quando da Cúpula do Milênio, promovida pela Organização das Nações Unidas, com a participação de 189 países, a prioridade máxima é a erradicação da fome e da extrema pobreza até 2015. Para tanto, são essenciais ações que con- 
templam saneamento, educação, habitação, promoção de igualdade de gêneros e de preservação do meio ambiente, mas essencialmente, ações de saúde devidamente difundidas, e, portanto, ao mesmo tempo, geratrizes e resultantes de pesquisas em informação em saúde. Afinal, a desigualdade social em território brasileiro ainda é muito grave. Segundo Aranha (2005), em 1992, 22\% se apropriam de 55,7\% da renda nacional; em 1996, de $55,8 \%$ e em 2002 , sobe para $56,8 \%$. Isto significa que se o Brasil está prestes a atingir as duas metas do objetivo número um - erradicar a extrema pobreza e a fome - ainda há muito a ser feito.

Com base no discutido, recomendamos:

- adoção da estratégia de microrregiões para avaliação dos sistemas de informação, com o intuito e identificar as áreas de difícil coleta de dados.

- investimento prioritário no gerenciamento dos sistemas de informação em nível regional, estadual e municipal, com vistas à cobertura e qualidade satisfatórias dos sistemas de informação.

- introdução sistemática e devidamente orientada da análise da consistência da informação nos três níveis, no sentido de aprimorar a qualidade da informação e eficiência dos sistemas de informação em saúde, em áreas de boa cobertura ou precária.

- emprego de técnicas de controle da qualidade da informação (levantamentos amostrais para validação dos dados com os prontuários médicos; adoção de confrontos entre os sistemas de informação; emprego de técnicas variadas etc.) no caso de áreas com boa cobertura dos sistemas de informação.

- maior racionalidade na utilização da Internet via infoeducação, com treinamentos sistemáticos aos que estão do outro lado da linha - técnicos encarregados da coleta de dados que alimentam as bases e bancos de dados e / ou os cidadãos comuns que se alimentam das informações oficiais mantidas pelo Datasus.

- popularização das informações em saúde.

Esta última é a nossa sugestão máxima. O ideal é que cientistas, pesquisadores e profissionais de saúde em qualquer instância recorram a modalidades múltiplas para divulgação de suas pesquisas, seus trabalhos, seus programas de saúde, suas campanhas e assim por diante, respeitando as singularidades das especialidades e das circunstâncias. 
É o momento de maior valoração do jornalismo científico. É o momento de eventos, como as conferências anuais de comunicação e saúde, que ocorrem desde 1998, com a finalidade de refletir sobre questões teóricas e práticas, com vistas a implementar práticas de saúde voltadas para a sociedade, à semelhança da VIII Comsaúde, em 2005, realização da Universidade do Vale do Rio dos Sinos.

Não há regra única e uníssona. Há formas distintas de registro e disseminação, dentro da concepção de que a divulgação é tão importante quanto as demais etapas da investigação científica e / ou dos estudos e políticas sociais públicas. Há que se buscar alternativas e estratégias distintas, como a difusão de informação em saúde via rádio (ainda, a mídia de maior circulação), a ampliação dos números de telefone para informação grátis, folders e cartilhas de fácil compreensão, cartazes, outdoors etc. Tudo em qualquer lugar: postos de saúde, sedes de associações de classe ou de bairro, igrejas (qualquer que seja o credo), televisão, escolas nos três níveis etc. etc.

\section{REFERÊNCIAS}

ALMEIDA, M. F. de; ALENCAR, G. P. Informações em saúde: necessidade de introdução de mecanismos de gerenciamento dos sistemas. Informe Epidemiológico do SUS, Brasília, v. 9, n. 4, p. 241-249, 2000.

ARANHA, A. V. Da política de segurança alimentar e nutricional. In: SOUSA, R. M. S.; TARGINO, M. das G; SANTOS, S. M. de J. Fome Zero e múltiplas facetas. Brasília: MDS / Programa Fome Zero, 2005.

BIOMED CENTRAL. Welcome to BioMed Central. Disponível em: <http://www. biomedcentral.com>. Acesso em: 2 set. 2008.

BRASIL. Ministério da Ciência e Tecnologia (MCT). Estatísticas e indicadores. Disponível em: <http://www.mct.gov.br>. Acesso em: 22 set. 2008a.

BRASIL. Ministério da Saúde (MS). Banco de Dados do Sistema Único de Saúde. Disponível em: <http://www.datasus.gov.br>. Acesso em: 27 set. 2008b.

[Sistemas de informações sobre...] Disponível em: <http://www.datasus. gov.br>. Acesso em: 22 set. 2008c.

BUCHALLA, A. P. O consultório da Internet. Veja, São Paulo, v. 38, n. 37, p. 112-116, 14 set. 2005.

FRANÇA, L. D. de. O comportamento informacional dos profissionais médicos e enfermeiros do Programa de Saúde da Família (PSF) - Sistema Único de Saúde (SUS). 2002. 151 
f. Dissertação (Mestrado em Ciência da Informação) - Programa de Pós-Graduação em Ciência da Informação da Universidade Federal de Minas Gerais, Belo Horizonte, Belo Horizonte. 2002.

MÁRDERO ARELLANO, M. Á.; FERREIRA, S. M. S. P.; CAREGNATO, S. E. Editoração eletrônica de revistas científicas com suporte do protocolo OAl. In: FERREIRA, S. M. S. P.; TARGINO, M. das G. Preparação de revistas científicas: teoria e prática São Paulo: Reichmann \& Autores, 2005. p. 195-232.

MASCARENHAS, M. D. M. Avaliação da confiabilidade dos dados do Sistema de Informações sobre Nascidos Vivos em Teresina, Piauí. 2004. 60 f. Dissertação (Mestrado em Ciências e Saúde) - Centro de Ciências da Saúde da Universidade Federal do Piauí, Teresina. 2004.

MELLO JORGE, M. H. P. Registro dos eventos vitais: sua importância em saúde pública. São Paulo: Centro Brasileiro de Classificação de Doenças, 1990.

MORAES, Alice Ferry de. Ensino e pesquisa da Fiocruz: produtores científicos; relatório final. Rio de Janeiro: Fiocruz, 2005. 21 f. (Digitado).

PUBLIC LIBRARY OF SCIENCE (PLoS) About PLoS. About the PLoS journals. Disponível em: <http://www.plos.org>. Acesso em: 29 set. 2008.

SISTEMA REGIONAL DE INFORMACIÓN EN LÍNEA PARA REVISTAS CIENTÍFICAS DE AMÉRICA LATINA, EL CARIBE, ESPAÑA Y PORTUGAL (Latindex). Que es Latindex? Disponível em: <http://www.lantindex.org>. Acesso em: 2 ago. 2008.

TARGINO, Maria das Graças. Comunicação científica: o artigo de periódico nas atividades de ensino e pesquisa do docente universitário brasileiro na pós-graduação. 1998. 387 f. Tese (Doutorado em Ciência da Informação) - Departamento de Ciência da Informação e Documentação da Faculdade de Estudos Sociais Aplicados da Universidade de Brasília, Brasília. 1998.

TARGINO, Maria. das Graças; CASTRO, M. M. R. N. de. Perfil dos títulos dos periódicos do grupo de Publicações Eletrônicas em Medicina e Biologia (Grupo e-pub). In:

(Org.). Desafiando os domínios da informação. Teresina: UFPI, 2002. 313 p. p. $\overline{291-313 .}$

TOMÁEL, M. I. et al. Avaliação de fontes de informação na Internet: critérios de qualidade. Informação \& Sociedade, João Pessoa, v. 11, n. 2, p. 13-35, 2001.

THE UNITED KINGDOM PARLIAMENT. Science and technology tenth report. London: House of Commons, 2004. Disponível em: <http://www.publications.parliament.uk/pa/ cm200304/cmselect/cmsctech/399/ 39902.htm >. Acesso em: 22 set. 2005.

\section{Title}

Health Information: potential and limitations 


\section{Abstract}

The article aims to discuss information related to health and medical care area as a key element for the decision-making processes regarding public policies, which are directly responsible for the life quality's increase. In order to achieve this main objective, the information systems are focused. It also addresses the scientific communication, including the dissemination of results, with special emphasis in the potentialities and limitations of the information in this area. Finally, some suggestions are presented, with the main focus on the popularization of this type information.

\section{Keywords}

Health Information. Scientific dissemination.

\section{Titulo}

Información en salud: potencialidades y limitaciones

\section{Resumen}

Se intenta examinar la información en salud como elemento fundamental en el proceso de toma de decisiones en el centro de las políticas públicas, con el fin de elevar la calidad de vida de las naciones. Para ello, a priori, se reflexiona sobre los sistemas de información en salud. A partir de ahí, se resalta el proceso de comunicación científica, incluyendo la divulgación de resultados, enfatizando en las potencialidades y limitaciones de la información en salud. Finalmente, se presentan sugerencias, sobre todo, con vistas a la divulgación de esas informaciones.

\section{Palabras clave}

Información en salud; Divulgación científica

Recebido em: 28.10.2008

Aceito em: 04.08.2009 